\title{
Therapeutic Effects of Mesenchymal Stem Cells and Hyaluronic Acid Injection on Osteochondral Defects in Rabbits' Knees
}

\author{
Sung Soo Kim, $\mathrm{MD}^{1}$, Min Soo Kang, $\mathrm{MD}^{1,2}$, Kyu Yeol Lee, $\mathrm{MD}^{1}$, Myung Jin Lee, $\mathrm{MD}^{1}$, Lih Wang, $\mathrm{MD}^{1}$ and Hyo \\ Jong Kim, $\mathrm{MD}^{1}$ \\ Department of Orthopaedic Surgery, ${ }^{1}$ Dong-A University College of Medicine, ${ }^{2}$ Dong-Eui Medical Center, Busan, Korea
}

\begin{abstract}
Purpose: To evaluate the treatment results of intraarticular injection according to the frequency of hyaluronic acid with mesenchymal stem cells on the osteochondral defect of rabbits' medial femoral condyles.

Materials and Methods: A $5 \mathrm{~mm}$ diameter and $4 \mathrm{~mm}$ depth osteochondral defect was made on the medial femoral condyles of 18 rabbits, divided into six groups. One week after osteochondral defect, group B was injected intraarticularly with hyaluronic acid (HA), group C with mesenchymal stem cells (MSCs), and group D, E and F with both HA and MSCs. Group E and F received second HA injection a week after. Further, group F received third HA injection in the third week.

Results: In a macroscopic evaluation, groups B (6; range, 5-8), C (6; range, 6-7), D (7; range, 6-7), E (6.5; range, 6-8) and F (7.5; range, 6-8) showed statistically significant improvements in osteochondral defect healing, compared with that of group A (4; range, 3-5) ( $\mathrm{p}=0.002)$. In histological evaluation, groups B (11.5; range, 11-13), C (13; range, 12-18), D (16; range, 13-18), E (17.5; range, 13-20), and F (19.5; range, 12-22) showed statistically significant differences in osteochondral defect healing, compared with group A (8; range, 6-9) ( $\mathrm{p}=0.006)$.

Conclusions: The intraarticular injections of MSCs or HA can play an effective role during the healing osteochondral defects in rabbits.
\end{abstract}

Key words: Mesenchymal stem cell, Hyaluronic acid, Osteochondral defect, Rabbit.

\section{Introduction}

Joint cartilage is a highly differentiated tissue and structure. It is frequently injured, but has limited potential of recovery ${ }^{1)}$. Because of the limited capacity for regeneration following trauma, damaged articular cartilage typically degenerates over time, which eventually progresses to osteoarthritis. Periosteal

Received May 3, 2011; Revised June 26, 2011;

Accepted July 6, 2012.

Correspondence to: Min Soo Kang, MD.

Department of Orthopaedic Surgery, Dong-Eui Medical Center, 62,

Yangjung-ro, Busanjin-gu, Busan 614-710, Korea.

Tel: +82-51-850-8937, Fax: +82-51-850-8943

Email: kingmin8@empal.com

This is an Open Access article distributed under the terms of the Creative Commons Attribution Non-Commercial License (http://creativecommons.org/licenses/by-nc/3.0/) which permits unrestricted non-commercial use, distribution, and reproduction in any medium, provided the original work is properly cited. arthroplasty, perichondral arthroplasty, autologous osteochondral transplantation, autologous chondrocyte transplantation, autogenetic cancellous grafts and tendon autografts are methods that aim to form a new chondral surface ${ }^{2)}$. Autologous chondrocyte implantation has been frequently used in the clinic, but results from animal models demonstrate the inefficiency of this technique ${ }^{3,4)}$.

For successful cell based therapy, it is necessary to identify an appropriate cell source, which is easily accessible, possesses the ability to expand to large numbers, and has chondrogenic potential $^{5)}$. Among the numerous progenitor cell types, mesenchymal stem cells (MSCs), derived from bone marrow, have been extensively investigated, and have demonstrated a strong potential for cartilage regeneration ${ }^{6}$. MSCs have theoretical advantages, compared to the chondrocytes, regarding the potential for healing. These cells have the ability to proliferate without loosing their ability to differentiate into mature chondrocytes producing collagen II and aggrecan, or osteoblasts producing osteoid ${ }^{7)}$. Thus, MSCs may induce repair of both bone and cartilage in an osteochondral defect ${ }^{8,9)}$. However, to differentiate the MSCs to its 
target cell, scaffold is necessary.

There has been a study ${ }^{10)}$ describing the direct intra-articular injection of MSCs in a porcine model of large cartilage defect. The study confirmed that the injected MSCs were found in the neocartilage. The author used this study as the baseline for intraarticular injection of MSCs.

Rabbit experiments have shown that hyaluronan injections may improve the repair of osteochondral defects ${ }^{11}$, partial thickness defects ${ }^{5}$, and repair after microfracture ${ }^{12)}$. Loken et al. ${ }^{13)}$ reported that MSCs in a hyaluronic acid (HA) scaffold may be a promising treatment approach for osteochondral defect in a rabbit model. Funayama et al. ${ }^{14)}$ reported good result in rabbits' full-thickness articular cartilage defects, by using injectable type II collagen gel with cultured chondrocytes.

The purpose of this study was to test the hypotheses that injection of MSCs with HA will improve healing in an established model of an osteochondral defect in the rabbit knee, and additional HA injection will affect osteochondral defect.

\section{Materials and Methods}

\section{Subjects and Study Design}

Nineteen New Zealand white rabbits that were approximately 8 weeks old at the beginning of the experiment and weighed $2-2.5 \mathrm{~kg}$ were included in the study. One of them was used as a donor of MSCs, and thus, was excluded from this study after the collection of bone marrow. The animals were allowed to move freely in their cages 1 week before surgery, and most animals were immediately able to bear weight on both extremities after surgery. The protocol for the animal experiment was approved by the Institutional Animal Care and Use Committee (Approvement No. 09-13). The rabbits were handled according to the guidelines established for animal care at the center. Each rabbit had free access to both sterile water and standard rodent soft chow ad libitum.

Six groups, each with 6 knees of 3 rabbits, were classified as the control group and five research groups. Group A served as the control group without treatment. All animals were sacrificed seven weeks after the surgical reception of osteochondral defect. Each rabbit was sacrificed via carbon dioxide inhalation.

\section{Isolation and Expansion of Mesenchymal Stem Cells}

Bone marrow of the donor rabbit was collected under general anesthesia from the posterior superior iliac spine. About $3 \mathrm{~mL}$ bone marrow was aspirated with a syringe coated with $5 \mathrm{IU}$ heparin $/ \mathrm{mL}$ in a small animal operating room. Bone marrow aspirated was cultured and given at the same time.

Under sterile conditions, the blood containing phosphate buffered saline (PBS; bone marrow:PBS=1:1) was deposited over Ficoll-paque Plus ( $\mathrm{d}=1.077 \mathrm{~g} / \mathrm{mL}$, GE healthcare, Piscataway, NJ, USA). After centrifugation at 2,500 rpm for 10 minutes at room temperature, the dense gradient separated the erythrocytes and granulocytes into pellets in the bottom part of the tube; mononuclear cells were situated in an opalescent layer between the Ficoll and blood plasma.

This layer was taken out, then the cells were washed twice with culture medium and seeded in a $100 \times 20 \mathrm{~mm}$ Petri dish at a density of $2 \times 10^{6} \mathrm{cells} / \mathrm{cm}^{2}$ and cultured at $37^{\circ} \mathrm{C}$ in a humidified atmosphere with $5 \% \mathrm{CO}_{2}$. The culture medium was Dulbecco's modified eagle's medium (DMEM; Gibco, Grand Island, NY, USA), contained with $10 \%$ fetal bovine serum (FBS; Gibco), and penicillin/streptomycin $(50 \mathrm{U} / \mathrm{mL}$ and $50 \mu \mathrm{g} / \mathrm{mL}$, respectively; Gibco). After 3 days of culture, the non-adherent cells were removed and during the subsequent culture, the medium was changed every third day. The first colonies of marrow MSCs appeared after 4 to 5 days of culture, and $80 \%$ of confluence was achieved after 14 days of culture. When the primary cultures became nearly confluent, the cell was treated with $0.25 \%$ Trypsinethylenediaminetetraacetic acid solution (Gibco) for 5 minutes at $37^{\circ} \mathrm{C}$ and replated at a density of $1 \times 10^{6}$ cells $/ \mathrm{cm}^{3}$. Harvesting was done after 14 days of culture. After harvest of the floating cells, using a pipette, each rabbit received an intraarticular injection, at a density of $1 \times 10^{6}$ cells suspended in $200 \mu \mathrm{L}$ PBS.

\section{Injection and Sacrifice}

The animals were anesthetized using intramuscular ketamine of $30 \mathrm{mg}$. Intramuscular antibiotics (gentamycin $10 \mathrm{mg}$ ) were given twice in a day for 3 days postoperatively. With the use of a standard aseptic technique, both knees were approached through a medial parapatellar incision with the patella dislocated laterally. A $5 \mathrm{~mm}$ diameter and $4 \mathrm{~mm}$ depth defect was made in the central portion of the weight bearing area of the each medial femoral condyle with a dermal biopsy punch and manual debridement (Fig. 1). After one week, MSCs $\left(1 \times 10^{6}\right.$ cells $\left./ 0.2 \mathrm{~mL}\right)$ and/or HA (10 mg/1 mL, Hyruan Plus, LG Pharmacological Co., Seoul, Korea) were injected intraarticularly, after verifying by aspiration of joint fluid in the syringe.

Thirty six knees of 18 rabbits were divided into six groups: A, B, C, D, E, and F. Group A was served as the control group without treatment. One week after receiving the osteochondral defect, group B was injected with $\mathrm{HA}$, group $\mathrm{C}$ was injected with MSCs, and group D was injected once with both HA, and MSCs. 


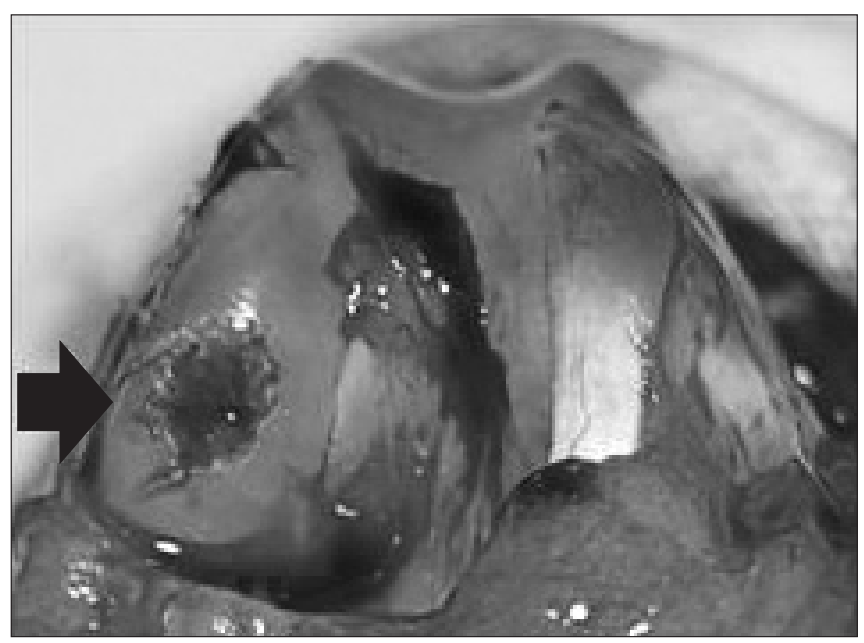

Fig. 1. Formation of an osteochondral defect on the weight bearing medial femoral condyle of rabbit (black arrow indicates $5 \mathrm{~mm}$-diameter, and $4 \mathrm{~mm}$-depth osteochondral defect).

In addition, group $\mathrm{E}$ was treated the same way as group $\mathrm{D}$, but received a second injection of HA a week after. Group F was treated the same way as group E, but received a third injection of HA in the third week.

\section{Macroscopic Evaluation}

The gross appearance of the defect was assessed by consideration of the degree of defect filling the surrounding normal cartilage, the color around the defect and the surface characteristics of the repair. The macroscopic evaluation consisted of a score, whereby a maximum of 8 and a minimum of 3 points were assigned by Rudert et al. ${ }^{15)}$ (Table 1). Osteochondral defects of sacrificed rabbits were photographed using a ten million pixel digital camera (Coolpix, Nikon, Tokyo, Japan) (Fig. 2).

\section{Histological Evaluation}

Soft-tissue attachment was severed, and the distal femoral condyles were excised and placed into a $4 \%$ paraformaldehyde fixative. After fixation, the distal femur was decalcified with $10 \%$ formic acid. Blocks were prepared for processing using longitudinal dissection of the defect center. Samples were then dehydrated using a graded series of alcohol and xylene washes, and then embedded with paraffin. Sections were cut to $5 \mu \mathrm{m}$, which were then stained with hematoxylin-eosin and toluidine blue. Toluidine blue allowed assessing metachromatic staining of cartilage matrix due to proteoglycan content.

Sections were viewed under a light microscope and graded semi-quantitatively, using the modified International Cartilage Repair Society (ICRS) score (Table 2). The scoring system was
Table 1. Macroscopic Scoring System for Cartilage Healing by Rudert et al. $^{15)}$

\begin{tabular}{lc}
\hline \multicolumn{1}{c}{ Category } & Score \\
\hline Filling & 3 \\
Flush with surrounding cartilage & 2 \\
Up to surrounding cartilage with central depression & 1 \\
Distinct underneath surrounding cartilage & \\
Color & 3 \\
Cartilaginous, same as surrounding cartilage & 2 \\
White & 1 \\
Brown or yellow & \\
Surface & 2 \\
Smooth & 1 \\
Rough & \\
\hline
\end{tabular}

based on the percentage of the defect that was filled, articular surface continuity, restoration of osteochondral architecture, repair tissue integration, cellular morphology of articular cartilage regeneration, and matrix staining (metachromasia).

\section{Statistical Analysis}

Data analysis was performed with SSPS ver. 15.0 (SPSS Inc., Chicago, IL, USA). Comparisons between the groups were carried out using a Kruskall Wallis test. Values with $\mathrm{p}<0.05$ were considered statistically significant.

\section{Results}

\section{Macroscopic Findings}

In group $\mathrm{A}$, the fillings of defected portions were distinct underneath the surrounding cartilage, and the colors were brownish, in addition to the surfaces being rough. The macroscopic scores of group A were 4 (range, 3-5). In groups B and $\mathrm{C}$, the fillings of defected portions were recovered up to the surrounding cartilage, but showed central depression, and the colors were whitish; surfaces between smooth and rough were observed. The macroscopic scores of groups $\mathrm{B}$ and $\mathrm{C}$ were both 6 (range, 5-8) (range, 6-7). In groups D and E, the fillings were flush with the surrounding cartilage, but some showed central depression and the colors were whitish; surfaces between smooth and rough were observed. The macroscopic scores of group $\mathrm{D}$ and group E were 7 (range, 6-7) and 6.5, respectively (range, 6-8). In group F, the fillings of defected portions were flush with the surrounding cartilage, the colors were cartilaginous (the same as the surrounding tissue), and the surfaces were smooth. The 


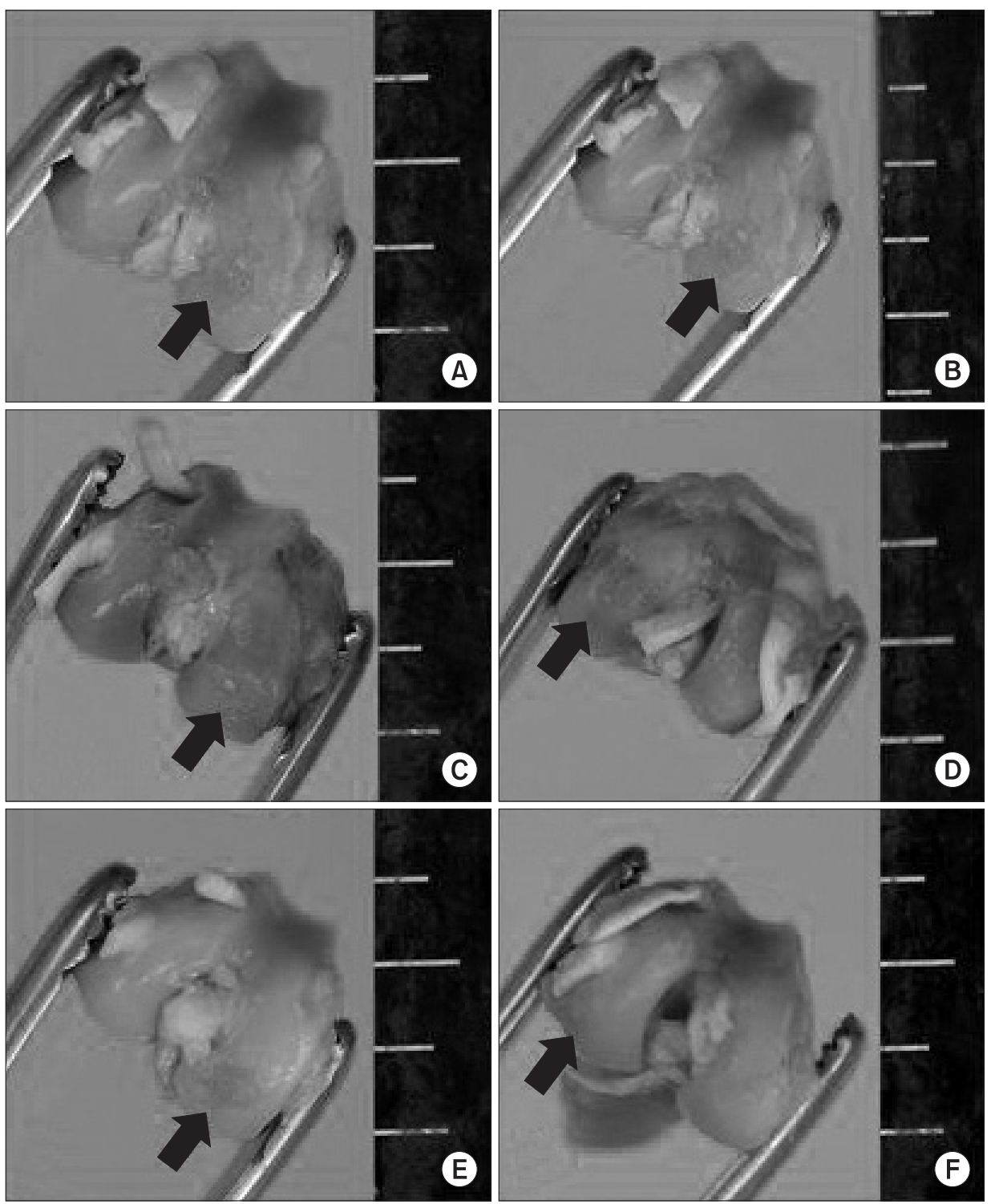

Fig. 2. Gross appearance of distal femur of rabbit after sacrificing (black arrow indicates osteochondral defect, ruler scale at right side of each photographs is shown with gradations in mm). (A) Macroscopic findings of group A shows distinct defect filling surrounding normal cartilage and brown and rough articular surface. (B-E) Macroscopic findings of group B, C, D, and E show relativly smooth and white articular surface filled up to surrounding cartilage but central depression. (F) Macroscopic findings of group $\mathrm{F}$ shows smooth and undistinguishable articular surfaces which were well filled. macroscopic scores of group F were 7.5 (range, 6-8).

In Macroscopic findings, group A showed worse recovery than the other groups $(\mathrm{p}=0.002)$. However, there was no significant difference in the recovery among the groups, except group A ( $>0.05$ ) (Table 3, Fig. 2).

\section{Histological Findings}

In group $\mathrm{A}$, the defected portions showed fillings below $50 \%$, surfaces between rough and discontinuous, heterologous to poor restorations of osteochondral architecture, partial to poor repairs of tissue integration, cellular morphologies, which were from hybrid to fibrocartilage, and markedly reduced staining. The ICRS scores were 8 (range, 6-9). In group B, the defected portions showed fillings between $50 \%$ and $75 \%$, rough surfaces, unclear restorations, partial repairs, cellular morphologies without zonal architecture or morphologies with hybrid features and reduced staining. The ICRS scores were 11.5 (range, 11-13). In group C, the defected portions showed fillings from $50 \%$ to $100 \%$, rough surfaces, heterologous restorations, complete to partial repairs, cellular morphologies without zonal architecture and reduced staining. The ICRS scores were 13 (range, 12-18). In groups D and $\mathrm{E}$, the defected portions showed fillings from 50\% to $100 \%$, smooth surfaces, differentiable restorations, complete to partial repairs, cellular morphologies with or without zonal architecture and normal to reduced staining. The ICRS scores of group D were 16 (range, 13-18), and group E were 17.5 (range, 13-20). In group $\mathrm{F}$, the defected portions showed fillings from $75 \%$ to $100 \%$, continuous and smooth surfaces, clearly differentiable 
Table 2. Semi-quantitative Articular Cartilage Repair Scoring System by Modified International Cartilage Repair Society Score

\begin{tabular}{|c|c|}
\hline Category & Score \\
\hline \multicolumn{2}{|l|}{ Percentage defect filling } \\
\hline $100 \%$ & 4 \\
\hline $75 \%$ & 3 \\
\hline $50 \%$ & 2 \\
\hline $25 \%$ & 1 \\
\hline $0 \%$ & 0 \\
\hline \multicolumn{2}{|l|}{ Articular surface continuity } \\
\hline Continuous and smooth & 3 \\
\hline Continuous but rough & 1 \\
\hline Discontinuous & 0 \\
\hline \multicolumn{2}{|l|}{ Restoration of osteochondral architecture } \\
\hline Clearly differentiable & 4 \\
\hline Unclear (heterologous) & 2 \\
\hline Poor (osseous-chondral compartmentation) & 1 \\
\hline Nonexistent & 0 \\
\hline \multicolumn{2}{|l|}{ Repair tissue integration } \\
\hline Complete & 3 \\
\hline Partial & 1 \\
\hline Poor & 0 \\
\hline \multicolumn{2}{|c|}{ Cellular morphology of articular cartilage regeneration tissue } \\
\hline Hyaline with zonal architecture & 5 \\
\hline Hyaline without zonal architecture & 3 \\
\hline Hyaline fibrous cartilage hybrid & 2 \\
\hline Fibrocatilage & 1 \\
\hline Fibrous tissue & 0 \\
\hline \multicolumn{2}{|l|}{ Matrix-staining (metachromasia) } \\
\hline Normal (compared with host adjacent cartilage) & 3 \\
\hline Slightly reduced & 2 \\
\hline Markedly reduced & 1 \\
\hline No metachromatic stain & 0 \\
\hline
\end{tabular}

restorations, complete to partial repairs, cellular morphologies with zonal architecture and normal staining. The ICRS scores were 19.5 (range, 12-22).

In histologic findings, group A showed worse scores than the other groups $(\mathrm{p}=0.006)$. There was no significant difference in the scores among the groups B, C, D, and E statistically ( $\mathrm{p}>0.05)$. Group F showed better scores than the other groups $(p=0.003)$ (Table 4, Fig. 3).
Table 3. Macroscopic Scores of Each Group

\begin{tabular}{|c|c|c|c|c|c|c|}
\hline & $\begin{array}{c}A^{a)} \\
(n=6)\end{array}$ & $\begin{array}{c}B^{b)} \\
(n=6)\end{array}$ & $\begin{array}{c}C^{c)} \\
(n=6)\end{array}$ & $\begin{array}{c}\mathrm{D}^{\mathrm{d})} \\
(\mathrm{n}=6)\end{array}$ & $\begin{array}{c}\left.E^{e}\right) \\
(n=6)\end{array}$ & $\begin{array}{c}F^{f)} \\
(n=6)\end{array}$ \\
\hline & & & & & & \\
\hline & & & & & & \\
\hline & & & & & & \\
\hline . & & & & 210 & 0.5 & 1.0 \\
\hline \multicolumn{7}{|c|}{$\begin{array}{l}\text { as control, }{ }^{\text {b) }} \text { Group } \\
\text { after ostechondral } \\
\text { stem cells (MSCs) } \\
\text { jected with MSCs } \\
\text { as treated with the } \\
\text { week, }{ }^{\text {f) }} \text { Group F as }\end{array}$} \\
\hline
\end{tabular}

\section{Discussion}

We found that the intra-articular injection of MSCs with HA improved healing in an established model of an osteochondral defect in the young rabbit knee. MSCs are multipotent cells that can differentiate into a variety of cell types (including osteoblasts, chondrocytes, myocytes, adipocytes, and beta-pancreatic islets cells) by the action of various transforming growth factor- $\beta$ family members ${ }^{15)}$. The MSCs is currently thought to be a source of cells for regenerative medicine. One study ${ }^{3)}$ has shown that MSCs can survive and thrive without a scaffold, and the injected stem cells have been recovered in viable form in a goat knee with simulated arthritis. Another study ${ }^{10)}$ for large cartilage defects with the porcine model showed that the intra-articular injected MSCs group had exhibited improvements of the cartilage healing, compared with the controls. Two previous studies ${ }^{16,17)}$ have used hyaluronan scaffold with and without MSCs in rabbits. Radice et al. ${ }^{16)}$ did not find any differences between with or without MSCs, but Kayakabe et al. ${ }^{17)}$ observed a better filling compared to the empty defects only when fibroblast growth factor-2 was added to the MSCs loaded hyaluronan scaffold. In our study, group C (MSCs only) showed better results than group A (no treatment). Thus, MSCs have positive effects on cartilage regeneration in osteochondral defect in the animal models. However, the filling cartilage was fibrous tissue, not hyaline tissue.

The recovery processes of osteochondral defects are not known in detail; but if they are not treated, complications will arise in the healing of the lesions ${ }^{18,19)}$. In such cases, which encompass a large part of the bone surface, damage may progress to the degeneration in joints. Although many methods have been developed for the treatment of chondral and osteochondral 
Table 4. Modified International Cartilage Repair Society Scores of Each Group

\begin{tabular}{|c|c|c|c|c|c|c|}
\hline & $A^{a)}(n=6)$ & $\mathrm{B}^{\mathrm{b})}(\mathrm{n}=6)$ & $C^{c)}(n=6)$ & $\mathrm{D}^{\mathrm{d})}(\mathrm{n}=6)$ & $E^{e)}(n=6)$ & $\left.F^{f}\right)(n=6)$ \\
\hline Percentage defect filling & $2(1-2)$ & $2.5(2-3)$ & $3(2-4)$ & $3(2-4)$ & $3(3-4)$ & $3.5(3-4)$ \\
\hline Articular surface continuity & $1(1-1)$ & $1(1-3)$ & $1(1-3)$ & $3(1-3)$ & $3(1-3)$ & $3(1-3)$ \\
\hline Restoration of osteochondral architecture & $1.5(1-2)$ & $2(2-2)$ & $2(2-4)$ & $2(2-4)$ & $3(2-4)$ & $4(2-4)$ \\
\hline Repair tissue integration & $1(0-1)$ & $1(1-3)$ & $2(1-3)$ & $2(1-3)$ & $2(1-3)$ & $3(1-3)$ \\
\hline Cellular morphology & $2(1-2)$ & $3(2-3)$ & $3(2-5)$ & $3(3-5)$ & $3(3-5)$ & $4(3-5)$ \\
\hline Matrix-staining (metachromasia) & $1(1-2)$ & $2(1-2)$ & $2(1-2)$ & $2(1-3)$ & $2(1-3)$ & $3(2-3)$ \\
\hline Total score & $8(6-9)$ & $11.5(11-13)$ & $13(12-18)$ & $16(13-18)$ & $17.5(13-20)$ & $19.5(12-22)$ \\
\hline
\end{tabular}

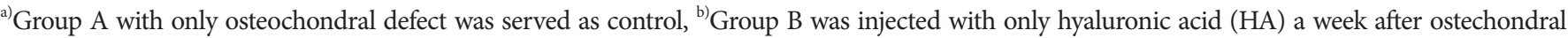

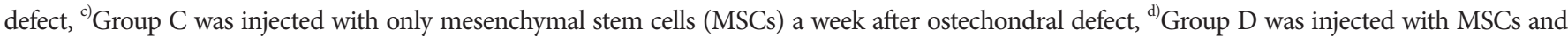
HA a week after ostechondral defect, ${ }^{\mathrm{e})}$ Group E was treated with the same way of group D and injected with HA after a week, ${ }^{\mathrm{f}}$ Group F as treated with the same way of group E and injected with HA after a week.

defects, none has been observed to result in the formation of normal cartilage $e^{20}$. From many recent studies, the best treatment method for focal defects remains unknown. Intra-articular HA application has anti-inflammatory, anabolic, analgesic, and cartilage protective effects, besides its physical effects, which refer to the injection of HA into joints as viscosupplementation ${ }^{21,12)}$. Takahashi et al. ${ }^{22)}$ stated that HA produces therapeutic effects by suppressing the production of nitric oxide. Intra-articular injection of HA increases the lubrication in synovial joints, and increases the friability, which is lowered in empirically formed osteoarthritis $^{23,24)}$. Furthermore, it decreases the concentration of fibrolytic factors whose numbers rise during the progress of osteoarthritis, and it causes a rise in glycosaminoglycan levels that form the inner structure of the cartilage matrix. However, there are some who suggest that further research is required on the cartilage-protective effects of HA. Strauss et al. ${ }^{12)}$ stated that supplementing the microfracture technique with 3 weekly injections of intra-articular HA had a positive effect on the repair tissue that formed within the chondral defect at the early followup time point. Kang et al. ${ }^{24)}$ demonstrated that exogenously supplied HA enhances the quality of the regenerated articular cartilage. Although it is possible that different cells pools (bone marrow, synoviocytes, chondrocytes) contribute to the cartilage regeneration process, the mesenchymal progenitor cells, migrating from the bone marrow, appear to be the main contributor $^{25}$. The introduction of an appropriate material into the defects provides scaffolding for the endogenous mesenchymal progenitor cells to adhere, migrate, and differentiate; thus, it may stimulate the cartilage regeneration process ${ }^{26)}$. HA, a major component of cartilage, recreates an embryonic-like environment that is favorable for the cartilage regeneration process ${ }^{27,28}$. In this study, groups that were treated with HA showed improvement in osteochondral defect healing, compared with the untreated group. Furthermore, the fact that groups treated with HA, and MSCs showed well differentiated osteochondral architecture, compared with the group treated with only MSCs, suggests that HA made to help MSCs to differentiate chondrocyte or osteoblast and differentiated chondrocyte or osteoblast regenerated osteochondral architecture. Differentiation of MSCs to specific cells is probably up to the scaffold, which makes the environment for MSCs. We applied no scaffold for MSCs, the injected HA may act as the scaffold. Group D showed a better cellular morphology than group C. Differentiation of cells in group D supports the injected HA acts as a scaffold.

Furthermore, this study could not really show that the injected MSCs were seeded on the defect sites, and further study is needed to include immunofluorescence-labelled MSCs to know if the injected MSCs survive at the defect site and differentiate to chondrocyte. Yet, many studies support that intraarticular injection is available. Lee et al. ${ }^{10)}$ confirmed that CFDA-SElabeled MSCs under fluorescence microscopy were found in the neocartilage. Murphy et al. ${ }^{29)}$ showed that intra-articular injection of MSCs in the goat model of osteoarthritis reduced the degeneration of the articular cartilage.

In this experimental design, the author could not exclude spontaneous healing effect on osteochondral defect. One study ${ }^{30}$ showed in young rabbits that it takes 6 weeks to regenerate osteochondral defect. Actually, osteochondral lesions are more frequent to the aged, but results of this study were limited to young specimens. A further study with older rabbits and longer follow up period following this is required to know degenerative effect on osteochondral lesion. Potential deterioration of this neocartilage could be observed if the author had a longer period of follow-up. 

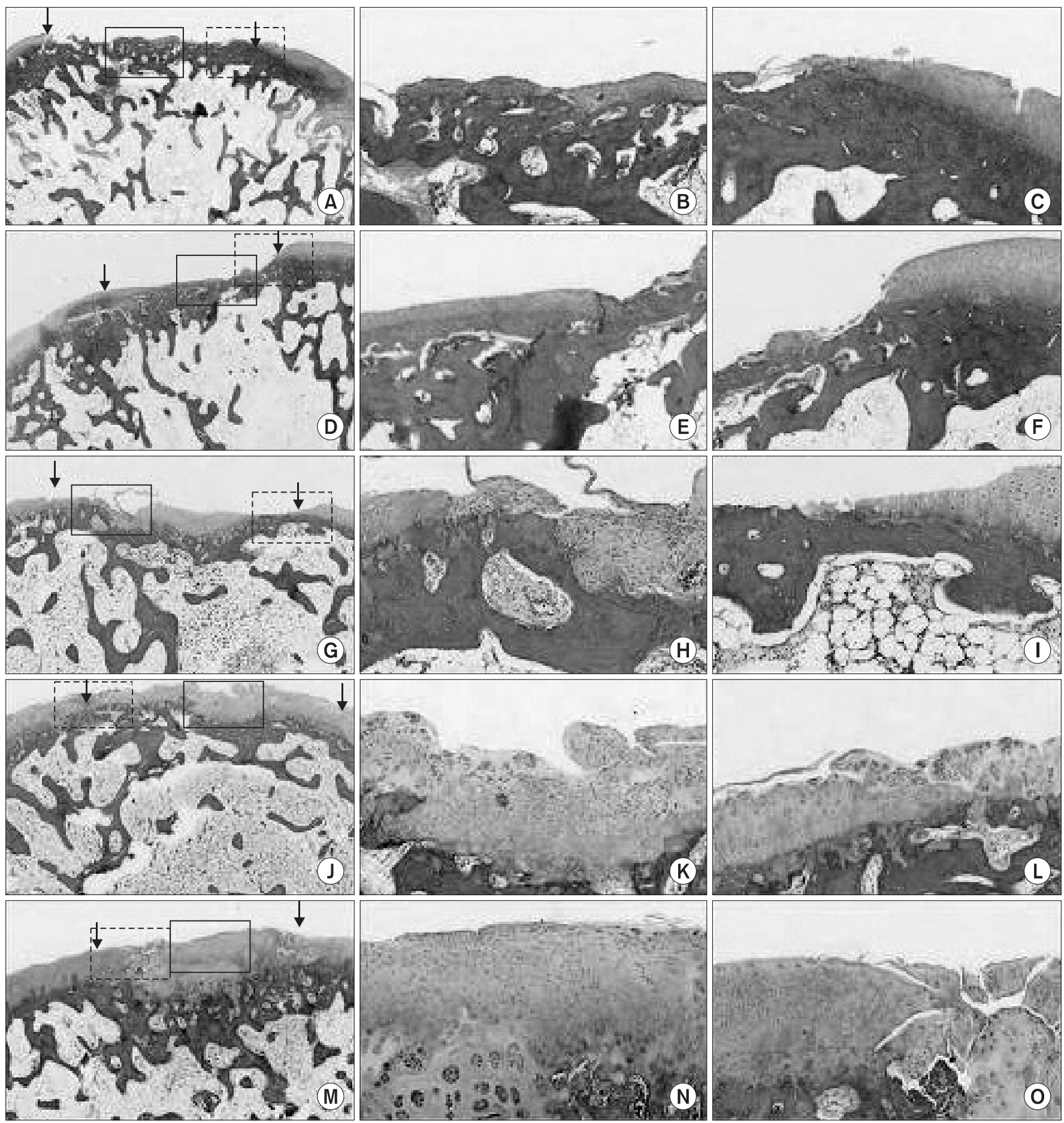

Fig. 3. Histologic findings of distal femur in rabbit after sacrificing. (A-C) Histologic findings of group A show surfaces between rough and discontinouos, poor restoration of osteochondral architecture, and cellular morphologies with fibrocartilage. (D-F) Histologic findings of group B show rough articular surface, unclearly restoration, and cellular morphologies with hyaline fibrous cartilage hybrid features. (G-I) Histologic findings of group C show rough surfaces, heterologous restorations, and hyaline cellular morphologies without zonal architecture. (J-O) Histologic findings of groups D and $\mathrm{E}$ show smooth surfaces, differentiable restorations, and hyaline cellular morphologies with or without zonal architecture. (P-R) Histologic findings of group F shows continuous and smooth surfaces, clearly differentiable restorations, and hyaline cellular morphologies with zonal architecture (A, D, G, J, M, P: arrows indicate the interface between the defected area and normal cartilage, $\times 20$; B, E, H, K, N, Q: lined rectangle of left column shows regenerative osteochondral tissue, $\times 100$; C, D, F, I, L, O, R: dotted retangle of left column shows transitional zones, $\times 100$ ). Stained with H\&E and toluidine blue. 

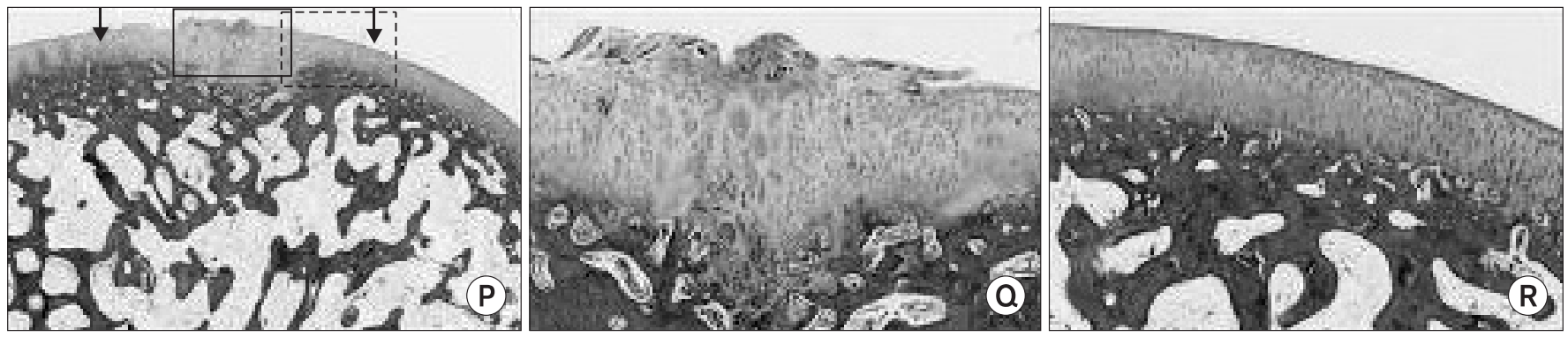

Fig. 3. Continued.

\section{Conclusions}

The intraarticular injections of MSCs and/or HA can play an effective role during the healing osteochondral defects in rabbits. Three weekly injection of HA with a single MSCs injection has a most effective role in osteochondral defects healing.

\section{References}

1. Sagliyan A, Karabulut E, Unsaldi E, Yaman I. Evaluation of the activity of intraarticular hyaluronic acid in the repair of experimentally induced osteochondral defects of the stifle joint in dogs. Vet Med. 2009;54:33-40.

2. Altman RD. Intra-articular sodium hyaluronate in osteoarthritis of the knee. Semin Arthritis Rheum. 2000;30:11-8.

3. Breinan HA, Minas T, Hsu HP, Nehrer S, Sledge CB, Spector M. Effect of cultured autologous chondrocytes on repair of chondral defects in a canine model. J Bone Joint Surg Am. 1997;79:1439-51.

4. Breinan HA, Minas T, Hsu HP, Nehrer S, Shortkroff S, Spector M. Autologous chondrocyte implantation in a canine model: change in composition of reparative tissue with time. J Orthop Res. 2001;19:482-92.

5. Jansen EJ, Emans PJ, Douw CM, Guldemond NA, Van Rhijn LW, Bulstra SK, Kuijer R. One intra-articular injection of hyaluronan prevents cell death and improves cell metabolism in a model of injured articular cartilage in the rabbit. J Orthop Res. 2008;26:624-30.

6. Barry FP. Mesenchymal stem cell therapy in joint disease. Novartis Found Symp. 2003;249:86-96.

7. Tuan RS, Boland G, Tuli R. Adult mesenchymal stem cells and cell-based tissue engineering. Arthritis Res Ther. 2003; 5:32-45.

8. Wakitani S, Yamamoto T. Response of the donor and recipient cells in mesenchymal cell transplantation to cartilage defect. Microsc Res Tech. 2002;58:14-8.
9. Yan H, Yu C. Repair of full-thickness cartilage defects with cells of different origin in a rabbit model. Arthroscopy. 2007;23:178-87.

10. Lee KB, Hui JH, Song IC, Ardany L, Lee EH. Injectable mesenchymal stem cell therapy for large cartilage defects: a porcine model. Stem Cells. 2007;25:2964-71.

11. Miyakoshi N, Kobayashi M, Nozaka K, Okada K, Shimada Y, Itoi E. Effects of intraarticular administration of basic fibroblast growth factor with hyaluronic acid on osteochondral defects of the knee in rabbits. Arch Orthop Trauma Surg. 2005;125: 683-92.

12. Strauss E, Schachter A, Frenkel S, Rosen J. The efficacy of intra-articular hyaluronan injection after the microfracture technique for the treatment of articular cartilage lesions. Am J Sports Med. 2009;37:720-6.

13. Loken S, Jakobsen RB, Aroen A, Heir S, Shahdadfar A, Brinchmann JE, Engebretsen L, Reinholt FP. Bone marrow mesenchymal stem cells in a hyaluronan scaffold for treatment of an osteochondral defect in a rabbit model. Knee Surg Sports Traumatol Arthrosc. 2008;16:896-903.

14. Funayama A, Niki Y, Matsumoto $H$, Maeno S, Yatabe T, Morioka H, Yanagimoto S, Taguchi T, Tanaka J, Toyama Y. Repair of full-thickness articular cartilage defects using injectable type II collagen gel embedded with cultured chondrocytes in a rabbit model. J Orthop Sci. 2008;13:22532.

15. Rudert M, Wilms U, Hoberg M, Wirth CJ. Cell-based treatment of osteochondral defects in the rabbit knee with natural and synthetic matrices: cellular seeding determines the outcome. Arch Orthop Trauma Surg. 2005;125:598-608.

16. Radice M, Brun P, Cortivo R, Scapinelli R, Battaliard C, Abatangelo G. Hyaluronan-based biopolymers as delivery vehicles for bone-marrow-derived mesenchymal progenitors. J Biomed Mater Res. 2000;50:101-9.

17. Kayakabe M, Tsutsumi S, Watanabe H, Kato Y, Takagishi K. Transplantation of autologous rabbit BM-derived 
mesenchymal stromal cells embedded in hyaluronic acid gel sponge into osteochondral defects of the knee. Cytotherapy. 2006;8:343-53.

18. Greenwald RA. Oxygen radicals, inflammation, and arthritis: pathophysiological considerations and implications for treatment. Semin Arthritis Rheum. 1991;20:219-40.

19. Aroen A, Loken S, Heir S, Alvik E, Ekeland A, Granlund OG, Engebretsen L. Articular cartilage lesions in 993 consecutive knee arthroscopies. Am J Sports Med. 2004;32:211-5.

20. Hunziker EB. Articular cartilage repair: basic science and clinical progress. A review of the current status and prospects. Osteoarthritis Cartilage. 2002;10:432-63.

21. Badiavas EV, Abedi M, Butmarc J, Falanga V, Quesenberry P. Participation of bone marrow derived cells in cutaneous wound healing. J Cell Physiol. 2003;196:245-50.

22. Takahashi K, Hashimoto S, Kubo T, Hirasawa Y, Lotz M, Amiel D. Hyaluronan suppressed nitric oxide production in the meniscus and synovium of rabbit osteoarthritis model. J Orthop Res. 2001;19:500-3.

23. Mankin HJ, Buckwalter JA. Restoration of the osteoarthrotic joint. J Bone Joint Surg Am. 1996;78:1-2.

24. Kang SW, Bada LP, Kang CS, Lee JS, Kim CH, Park JH, Kim BS. Articular cartilage regeneration with microfracture and hyaluronic acid. Biotechnol Lett. 2008;30:435-9.

25. Devine SM, Peter S, Martin BJ, Barry F, McIntosh KR. Mesenchymal stem cells: stealth and suppression. Cancer J. 2001;7 Suppl 2:S76-82.

26. Bartholomew A, Sturgeon C, Siatskas M, Ferrer K, McIntosh K, Patil S, Hardy W, Devine S, Ucker D, Deans R, Moseley A, Hoffman R. Mesenchymal stem cells suppress lymphocyte proliferation in vitro and prolong skin graft survival in vivo. Exp Hematol. 2002;30:42-8.

27. Solchaga LA, Yoo JU, Lundberg M, Dennis JE, Huibregtse BA, Goldberg VM, Caplan AI. Hyaluronan-based polymers in the treatment of osteochondral defects. J Orthop Res. 2000;18:773-80.

28. Solchaga LA, Gao J, Dennis JE, Awadallah A, Lundberg M, Caplan AI, Goldberg VM. Treatment of osteochondral defects with autologous bone marrow in a hyaluronan-based delivery vehicle. Tissue Eng. 2002;8:333-47.

29. Murphy JM, Fink DJ, Hunziker EB, Barry FP. Stem cell therapy in a caprine model of osteoarthritis. Arthritis Rheum. 2003;48:3464-74.

30. Wei X, Gao J, Messner K. Maturation-dependent repair of untreated osteochondral defects in the rabbit knee joint. J Biomed Mater Res. 1997;34:63-72. 